\title{
The Relationship Between Organisational Culture, Leadership Supportive Climate and Hospital Employees' Perception of Organisational Attractiveness and Level of Innovative Behaviour
}

Barbara Rebecca Mutonyi ( $\sim$ Barbara.lappalainen@inn.no)

Inland Norway University of Applied Sciences

\section{Terje Slåtten}

Inland Norway University of Applied Sciences

Gudbrand Lien

Inland Norway University of Applied Sciences

\section{Research Article}

Keywords: Organisational culture, Leadership support, Organisational attractiveness, Hospitals, Innovative behaviour, Employees

Posted Date: September 27th, 2021

DOl: https://doi.org/10.21203/rs.3.rs-850352/v1

License: (c) (1) This work is licensed under a Creative Commons Attribution 4.0 International License.

Read Full License 


\section{Abstract \\ Background}

Within the domain of health services research there has been little research focusing on how organisational culture is associated with leadership supportive climate and specifically whether and how organisational culture and leadership supportive climate either individually or mutually are related to employees' perception of the attractiveness of the organisation and employees' level of innovative behaviour. These knowledge gaps in previous research motivated the implementation of this study.

\section{Methods}

The conceptual model developed was tested on a sample $(N=1008)$ of hospital employees. Partial least squares structural equation modelling (PLS-SEM) was employed to test the conceptual models, using the SmartPLS 3 software. To test the mediator effect, a bootstrapping test was used, revealing whether the direct and indirect effects were statistically significant, and at the same time, when combining two tests, determining the type of mediator effect.

\section{Results}

The results can be summarized in four key findings: i) organisational culture was found to be positively directly related to leadership supportive climate $(\beta=0.87)$ and organisational attractiveness $(\beta=0.45)$, ii) leadership supportive climate was found to be positively directly related to both organisational attractiveness ( $\beta=0.22)$ and employees' individual innovative behaviour $(\beta=0.37)$, iii) the relationships between organisational culture, leadership supportive climate and employees' innovative behaviour were both found to be mediated through organisational attractiveness, iv) leadership supportive climate was found to mediate the relationship between organisational culture and organisational attractiveness as well as the relationship between organisational culture and employees' innovative behaviour.

\section{Conclusions}

Organisational culture and leadership supportive climate were highly correlated and imperative drivers to employees' perception of organisational attractiveness and employees' level of innovative behaviours. Managers of hospitals should consider organisational culture and leadership supportive climate as two organisational resources that are potentially manageable and controllable. Consequently, managers should actively invest in the two organisational resources. Such resource investment will lead to resource capitalisation manifested in both a growth in employees' perception of organisational attractiveness as well as employees' level of innovative behaviour. 


\section{Background}

Hospital organisations can be described and characterized as 'collections of people joined together in pursuit of a common cause and it is people who create value' [1]. The importance of the 'people factor' is also emphasized because hospital organisations are a part of those types of firms which often as a group are denoted as PSF or professional service firms [2]. Hospitals as PSF are reflected in their offerings provided 'by either an individual specialist or a team of specialists within a particular knowledge-based discipline' [3]. Consequently, regarding the critical role employees play, it becomes essential to understand the premises or foundations of how to orchestrate the hospital organisation in such a way that it contributes positively to strengthen employees' perception of the hospital organisation as an attractive place to work while simultaneously motivating individual employees to make progress in improvement in their work-role performance. Regarding the importance of the employees in hospital organisations, Slåtten et al. noted: 'because of the pure form of knowledge-based expertise ... it becomes ... essential for healthcare organizations to strive to promote or orchestrate a culture and climate that in the most positive way takes care of these core resources' [3].

An important aim of this paper is to examine whether and how hospital organisational culture and hospital organisational climate are capable, both individually and mutually, to promote desirable organisational objectives for hospital organisations. In general, organisational culture and climate have both been emphasized as fundamental aspects of organisations in the literature. For example, organisational culture has been described as something that 'pervades all aspects of organizational life' [4], something that provides 'the rules for behaviour' [5] and a potential source of organisational competitive advantage [6]. Similarly, organisational climate, stated as 'how things are done in this organization' reflected in whether there exists a supportive climate among leaders and employees, and how they can function as an important 'climatic conditions' for how well organisations are operating.

The literature suggests a variety of types of organisational culture and aspects of organisational climate that potentially could be included in a study of hospital organisations. However, this study focuses on concepts that are seldom researched within the domain of healthcare service research. Specifically, organisational culture is reflected in a concept that in this study is labelled internal market-oriented culture (IMOC). IMOC is based on ideas originally stemming from the marketing domain [7]. IMOC can be described as an organisational culture that has a clear direction towards and focus on employees in the organisation. Although there is little research on this concept, previous research reveals that IMOC is related to concepts such as employees' job satisfaction, turnover intention, work engagement and organisational attractiveness [3, 8]. However, regarding the newness, Slåtten et al. noted 'there is a need for additional research into several aspects related to the concept of IMOC' [3]. In their work, the authors suggest that future research should relate IMOC to climatic conditions such as leadership styles in hospital organisations. This study follows this recommendation and aims to examine how IMOC is related to leadership support for autonomy (SA) within hospital organisations. SA reflects employees' perception of the interpersonal climate between themselves and their nearest leader and whether their leader supports them to act autonomously in their work role. 
Although IMOC and SA in this study are conceptually different, representing different levels in the organisation (referring to culture level versus climatic level), the two concepts have two characteristics in common. First, both IMOC and SA focus on how help and provision of support in organisations are offered. Second, both IMOC and SA are considered as organisational resources reflecting that both are relatively under management control and therefore manageable. This latter aspect assumes there exists a potential to capitalise on IMOC and SA to the achievement of desirable outcomes for the hospital organisation. This study aims to examine two types of capitalisation of IMOC and SA. Specifically, motivated by the work of Slåtten et al. [3, 8], the authors suggest that future research should specifically relate IMOC to hospital employees' perception of organisational attractiveness (OA) [3] and employees' individual innovative behaviour (IIB) [8]. Both OA and IIB are highly relevant to include using the hospital as the empirical setting. Regarding OA, Trybou et al. noted that 'hospital attractiveness is of major importance' [9]. Regarding IIB, previous research has found positive innovative attitudes and behaviours, in this study embraced in IIB, to be a vital source for organisations seeking competitive advantage through people [10,11]. IIB has been termed a 'key organizational competence' [12]. However, there is very little research, especially in health organisations, investigating organisational culture as an antecedent to employee IIB. As Oppi et al. [13] noted regarding IIB in health organisations: 'studies investigating factors that shape innovative behaviour at work are scarce'.

This paper is organised in the following way: First, the conceptual model of the study is briefly explained. Second, each concept is described and defined followed by a discussion where relationships between concepts are hypothesized. Third a description of the methodology and findings from the empirical study are then presented. Fourth, the final part includes a discussion of the findings, and includes several proposals for future research as well as an overall conclusion of this study.

\section{Conceptual model of the study}

The conceptual model of this study is represented in Fig. 1. As seen on the left side of the figure, marked with a dotted line, IMOC and SA represent two distinctive, but on the other hand interrelated, types of 'organisational resources'. Specifically, IMOC captures the organisational culture resource while SA captures the organisational climate resource. Notably, the term 'resource' describes four common characteristics relevant to both IMOC and SA. First, both IMOC and SA constitute relatively intangible (in contrast to tangible) organisational resources. Second, neither IMOC nor SA are static resources but in contrast both are dynamic and potentially change (either positively or negatively) as time passes. Third, the term 'resource' also signals that there is a potential to capitalise on IMOC and SA and thus have the potential to contribute to hospital competitive advantage in comparison with other relevant hospitals. This latter reasoning is in line with the resource-based view (RBV) theory [14], which assumes that the constellation of resources is both idiosyncratic and heterogeneously distributed across firms. Fourth, and this follows the second characteristic, the term 'resource' implies a possibility for hospital organisation to manage and relatively control the two types of organisational resources (referring to IMOC and SA) and thus simultaneously an opportunity to invest actively in IMOC and SA in the hospital organisation. Thus, 
based on this, and represented in Fig. 1, the following logic is assumed: if hospital organisation undertakes a 'resource investment' in IMOC and SA, the outcome of such investment will potentially lead to a capitalisation manifested in positive growth in both employees' perception of OA as well as employees' level of innovative behaviour (IIB). Therefore, OA and IIB in Fig. 1 are termed 'resource capitalisation' because they both stem from and reflect an outcome of the two types of 'organisational resources', IMOC and SA.

As presented, both IMOC and SA are proposed to be directly and indirectly related to two types of resource capitalisations, namely, (i) hospital employees' perception of OA and (ii) hospital employees' level of IIB. In the following sections, the concepts and linkages between concepts in Fig. 1 are elaborated in detail.

\section{Conceptual framework}

In this section each concept in Fig. 1 is first described and followed by a discussion where relationships between concepts are hypothesized.

\section{Support for autonomy (SA)}

In this study, the concept SA relates to the interpersonal work context in organisations. As shown in Fig. 1, SA is considered as a type of climatic resource within the organisation and thus reflects that it is under management control and therefore relatively manageable. Specifically, a climatic concept of SA is about employees' perception of 'how things are done here' in the hospital organisation. SA embraces whether the 'interpersonal context is '... autonomy-supportive when managers provide a meaningful rationale for doing the tasks, emphasize choice rather than control, and acknowledge employees' feelings and perspective' [15]. SA reflects employees' perceptions of a positive and good leadership style. Based on this, SA refers to the relationship between employees and their direct leader and whether employees perceive this interpersonal context as encouraging, motivating and stimulating.

SA originally related to ideas within the domain of self-determination theory (SDT) [16]. Previous research has emphasized SDT as a highly relevant and appropriate framework when studying aspects associated with motivations in work contexts [17]. In SDT, there are two types of motivation, labelled (i) autonomous and (ii) controlled motivation. Autonomous motivation is an inner or self-determined driven type of motivation and means 'that the person behaves with a full sense of volition and choice' [15]. In contrast, controlled motivation is diametrical to autonomous motivation. It is an outer and non-self-determined type of motivation, meaning 'that the person engages in an activity with an experience of pressure and control' [15]. This study limits its focus to autonomous motivation. There are four reasons for this perspective when studying SA. First, and most fundamental, using SDT as a guiding theoretical framework, SA is closely associated with the autonomous motivation of a person $[15,18]$. Second, in work contexts (which is the context of this study), autonomy is for many employees considered as desirable and a preferred aspect and something individuals often actively seek in their work role. In line with this, Amundsen states: 'individuals who seek autonomy at work are often searching for inner 
motivational environments and situations that provide them the opportunity for self-determination, initiative and choice' [19]. Third, autonomous motivation is described as the 'highest quality of regulation' [15] that is associated with positive outcomes. Fourth, SA is especially effective when individuals are performing complex tasks. 'Complex tasks require creativity, deep processing of information, and information integration' [20]. This latter aspect associated with SA is especially relevant considering the focus on IIB in this paper.

\section{Internal market-oriented culture (IMOC)}

The concept of IMOC is viewed as an 'organisational culture purposely or intentionally directed toward employees in the organisation' [3]. Specifically, in this study, IMOC as presented in Fig. 1 is viewed as an organisational culture resource. IMOC focuses on employees and whether there exists a culture of supportiveness within the hospital organisation. There are five reasons for focusing on a supportive organisational culture, here termed IMOC. First, culture has previously been viewed as an essential part of any organisation $[4,21]$, and as such, a supportive organisational culture, emphasizes values that are internal and employee focused $[3,22,23]$. Second, organisational culture is a key factor in better understanding and sustaining 'the observable norm-based behaviour that constitutes organisational culture' [8]. Third, managing organisational culture in health organisations, especially IMOC, is perceived as an indispensable part of health system reform [21]. Fourth, organisational culture has been linked to better performance and termed a powerful determinant for long-term organisational success [21]. This is due to its 'ability to create a sense of identity and rules' [21], aiding organisations, especially health organisations, in achieving their goals. Fifth, hospital employees' knowledge about their organisational culture is an effective coping mechanism in this current fast-changing environment because knowledge can offer insights and solutions to problems health organisations are facing today [22].

Previous studies show that health organisations that focus on their organisational culture have resulted in positive outcomes, such as overall quality improvement and positive employee behaviours and attitudes [22, 24]. In addition, previous studies focusing on IMOC among frontline employees in health care found that IMOC has a positive influence on employees' overall job satisfaction [3] and employee engagement [8]. As such, previous research has proposed organisational culture as vital in health organisations [8, 22]. Supportive organisational culture relates to tangible and visible characteristics of organisational culture. In this study, IMOC reflects hospital employees' experience, beliefs and expectations regarding their organisational culture. As such, IMOC focuses on the relationship between the organisation and its employees, and whether employees identify the overall conditions of their organisation as motivating, inspiring and encouraging.

\section{Organisational attractiveness (OA)}

In this study, the concept of OA centres on whether people perceive the hospital organisation as a great place to work. According to Trybou et al., 'hospital attractiveness ... of major importance' [9]. In a similar vein, Yan et al. describe OA as 'the core values ... especially for the labour-intensive healthcare industry' [25]. Originally, OA stems from and within the domain of employer branding [26]. However, much of 
previous research on OA has narrowed its focus to external aspects related to recruitment [27] and how companies communicate to prospective applicants that 'our' organisation is a desirable place to work. It is important to appear attractive and actively 'sell' the hospital organisation as an attractive organisation to work for to potential new candidates. On the other hand, some would say that an even more fundamentally important perspective of $\mathrm{OA}$ is to be perceived as an attractive organisation in the reality of those who already are employed and work for the hospital organisation. The latter is focused on in this study. Studies have found that those (current employees) who perceive their organisation as attractive, which is synonymous with the term 'a great place to work' are four times more willing to give extra effort in their work role [28]. Therefore, and in contrast to the dominating focus in previous research, OA is emphasized from an internal and current employee perspective. In line with previous research taking this current employee perspective, OA is considered as an attitudinal construct [8]. Specifically, OA relates to current employees' overall attitude of whether they perceive their organisation as an attractive organisation to be employed in [8]. It is notable that the concept of OA potentially contains or embraces both cognitive and affective aspects of employees' perceptions when considering the attractiveness of their hospital organisation. Accordingly, OA reflects current employees' overall cumulative attitude and whether they are 'viewing the [hospital] organisation as a desirable entity' [29].

\section{Individual innovative behaviour (IIB)}

According to the Merriam-Webster dictionary, innovation can generally be broadly described as the introduction of something new or to a change made in an existing product, the idea of field. In the literature, one will find a variety of both definitions and types of innovations. According to Hult et al., innovation in an organisation can be manifested in a diversity of ways and places in the organisation such as a 'new product or service, a new production process, or a new structure or administrative system' [30]. Consequently, innovation could potentially occur everywhere in an organisation. However, innovation in this study is limited in its scope and perspective in three ways. First, it focuses on innovation associated with and directed towards employees in the hospital organisation. This means it is mainly employee initiated and driven. Second, the manifestation of innovation is related to the work role that employees possess. Third, innovation is studied at the individual employee level. These three aspects collectively embrace what is termed IIB. IIB refers to the use of novel ideas and solutions by employees to solve problems at work [31]. IIB is comprised of problem detection, promotion of new ideas and the actual application of novel ideas or solutions at work [32]. Therefore, IIB is closely related to everyday practices and employees' reflections on how things are done and their capability to come up with ideas for improvement in their work performance. Accordingly, IIB embraces or functions as a form of 'learning and knowledge creation, integrated into daily work practices' [33]. Consequently, IIB is an appearance of a 'specific form of change-oriented activity' [34] that reflects employees' application of new and useful ideas within their work role in the hospital organisation.

\section{Theoretical relationships between concepts}

As presented in Fig. 1, SA is assumed to have a direct impact on IIB. Previous research has shown that SA is associated with different types of positive outcomes, including job performance [20,35]. For example, 
in a study by Kanat-Maymon and Reizer [20], the authors found that supervisors' autonomy-supportive managerial style was, among other factors, positively associated with job performance in a sample of sports analysts [20]. Similarly, in a study undertaken in a healthcare setting, Gillet et al. [35] found that supervisor autonomy support was indirectly related to nurses' job performance. Gillet et al. [35] defined job performance as nurses' perception of their team's quality of work. In this study, job performance refers to employees' IIB. IIB embraces both (implicitly) a person's cognition (that is to think or be creative) as well as the explicit manifestation of a person's behaviour (that is to actually try out new ideas in practice).

$\mathrm{IIB}$ is demanding and can be characterized as a complex task to perform. Previous research suggests that a necessary foundation to deal with such complex tasks is autonomy. Maymon and Reizer state 'complex tasks ... tend to require a higher degree of ... autonomy' [20]. SA is, based on SDT, 'posited to facilitate the needs for autonomy' [15]. Based on this, it is assumed that when employees experience SA from their direct leader this should lead to a positive increase in employees' IIB. Research has yet to examine this linkage in a healthcare context. However, previous research supports a positive linkage between SA and employees' creative performance [36]. Furthermore, there is empirical evidence that autonomy of employees is associated with characteristics such as innovative behaviour [37], creative work involvement [38], creative self-efficacy and innovative activities [39]. Furthermore, a linkage between SA and IIB is also supported in the LMX (leader-member-exchange) theory. LMX theory builds on social exchange theory $[40,41]$. According to LMX theory, a leader has a unique relationship with each member of the organisation [38]. A high-quality relationship between leaders and members in an organisation is suggested to have several positive outcomes, such as improved job performance. Consequently, based on LMX theory, when employees perceive the existence of a high-quality relationship of SA from their direct leader, it is reasonable to assume that this constitutes a necessary foundation and, moreover, functions as a promoting factor that positively increases employees' IIB in organisations. Naturally, there is probably a variation in employees' perception of SA, ranging from low to high. However, in this study it is expected that the more a direct leader provides SA to employees the more it positively increases employees' IIB. Formally this relationship is stated in this hypothesis:

\section{Hypothesis 1: SA is positively related to employees' IIB}

As proposed in Fig. 1, this study proposes a linkage that is made up of two sub-steps that together constitute an interconnected chain. The first step in the chain suggests a direct relationship between SA and OA. This proposes that employees' perception of leadership style (referring to $S A$ ) is associated with employees' attitude towards the attractiveness of the organisation that employs them. However, this specific relationship is yet to be explored, and the literature provides empirical evidence and documentation that leadership style and how the leadership role is performed are strongly associated with the employees' perception of their organisation. For example, previous research within healthcare has revealed that the performance of management tasks and leadership style are significantly linked to the employees' attitudes. The attitudes of employees are reflected in such as their level of job satisfaction [5], work engagement [42], turnover intentions [43] and a range of other work- and organisation-related factors. In this study, employees' perception of OA is defined as an attitude. Consequently, the 'list' of 
types of employee attitudes influenced by leadership in organisations should also include OA. Therefore, there are good reasons to assume a direct relationship between SA and OA. This is formulated by this hypothesis:

\section{Hypothesis 2: SA is positively related to $O A$}

As mentioned above, the first sub-step is proposed as the relationship between SA and OA. When this first step of linkages is established (referring to SA-OA linkage) this should lead to the second step of linkage, which is between OA and IIB. As such, this study also suggests, as presented in Fig. 1, that the relationship between SA and IIB is mediated through OA. This relationship represents an additional and complementary 'route' of how SA promotes IIB to what was proposed in the first hypothesis. According to Reeve, SA of leaders is 'a coherent cluster of supervisory behaviours that collectively create that interpersonal tone of support and understanding' [44]. Consequently, when employees perceive the SA of the leader as favourable and positive, this should strengthen employees' attitudes towards the attractiveness of the organisation that employs them. This positive attitude of employees regarding SA could be manifested in OA expressions such as: 'this is a great place to work' or this is a 'great employer'. Similar to the relationship between SA and OA, no previous research has examined the specific association between OA and IIB as a type of job performance. However, the literature supports OA to be linked to the employee's job performance. For example, in a study undertaken in healthcare settings, Slåtten et al. [8] found that OA was positively significantly associated with job performance. Job performance was in this study reflected in the level of service quality provided to hospital patients and employees' work engagement [8]. Moreover, Fortune 100 Best Companies to Work For also suggests there should be a linkage between $\mathrm{OA}$ and job performance, stating: 'employees who say they have a great place to work (or what this study labels as $\mathrm{OA}$ ) were four times more likely to say they're willing to give extra to get the job done' [45]. Social cognitive theory (SCT) also provides theoretical underpinnings to assume an association between OA and IIB. SCT suggests that '... beliefs and motivations are formed on valuable judgments' [46]. Based on this assumption from SCT there are good reasons to expect that when employees judge OA more positively it should strengthen employees' motivation to perform IIB. The discussion above suggests $\mathrm{OA}$ is functioning as a common link or a mediator between SA and IIB. Specifically, it means when employees perceive SA of leaders more positively this should lead to more positive attitudes towards OA of employees. Next, when OA increases, this should strengthen employees' motivation to make more use of their capability to experiment with novel ideas and to find creative solutions when performing their work role thus causing a positive increase in IIB of employees. This chain of linkages can formally be stated in this hypothesis:

\section{Hypothesis 3: OA mediates the relationship between SA and employees' IIB}

Figure 1 also suggests that IMOC has a direct impact on SA. Simultaneously, SA is assumed to function as a mediator between IMOC and both $\mathrm{OA}$ and IIB. The idea for both these relationships assumes that there must be some fundamental premises in place that are capable of cultivating and promoting $S A$ that simultaneously in the next round are capable to have an impact on both the perception of OA and 
employees' level of IIB. This 'engine' or must-be-factor that triggers and initiates this 'domino effect' is suggested to be IMOC. IMOC is, as also mentioned in the previous discussion, defined and described in terms of being a type of organisational culture. Previous research has well documented and emphasized the fundamental importance and role of organisational culture in organisations. Organisational culture is said to 'pervade all aspects of organisational life' [4]. When focusing on culture in organisation one looks at 'more fundamental characteristics of organisation' [47]. The importance of organisational culture lies in its proposition as a 'critical first step towards creating a satisfactory work environment' [4]. For example, organisational culture 'provides the rules for behaviour within organisations' [5]. These 'rules', stemming from organisational culture, are transferred to all organisational members. The transmission is not limited to only include employees. It also embraces the managers and leaders of the organisation and function as guiding principles of what is appropriate behaviour and how to practise their work role as managers or leaders. There is a linkage between organisational culture and leadership behaviour. As Banaszak-Holl et al. stated: 'organisational culture provides a key mechanism by which top management integrate managerial actions' [4]. Previous research supports well a positive association between organisational culture and leadership behaviour. This positive relationship is also found in healthcare research $[5,48]$. Consequently, parallel to findings in previous research, there are good reasons to expect organisational culture in this study to represent the concept of IMOC, to be positively associated with the SA of leaders. This leads to the following hypothesis:

\section{Hypothesis 4: IMOC is positively related to $S A$}

As mentioned in the discussion above, IMOC in an organisation provides directions and behavioural codes of conduct for the SA of organisations' leaders. Consequently, when IMOC positively increases the level of SA of leaders, this should also next lead to a positive increase both in employees' perception of $\mathrm{OA}$ and employees' IIB in an organisation. Specifically, in this study, it is expected that the stronger the existence of IMOC in an organisation is, the more positively it drives SA of leaders and in the next round both $\mathrm{OA}$ and IIB of employees. Accordingly, IMOC functions as an initial promoting factor to employees' perception of OA and level of IIB that works through the mechanism encompassed by leaders' SA. Consequently, it is expected that SA has a mediating role between IMOC and both OA and IIB. Based on the aforementioned discussion, the following two hypotheses are proposed:

\section{Hypothesis 5: SA mediates the relationship between IMOC and OA}

\section{Hypothesis 6: SA mediates the relationship between IMOC and employees' IIB}

According to Fig. 1, IMOC is assumed to have a direct impact on IIB. Previous research has indicated that in health organisations where there is a supportive organisational culture, which is directed towards employees, it can potentially be a source of competitive advantage [49]. Scott et al. [50] argued that 'structural changes alone do not deliver anticipated improvements in quality and performance in health care'. Consequently, organisational culture should play a key to improvements in quality and performance for health organisations. For example, Hogan and Coote [51] explored the role of organisational culture in professional service firms and found the organisational culture to be a key variable in fostering IIB at 
work. Similarly, Homburg and Pflesser [47] found the organisational culture to be directly related to the performance of employees. In this study, performance refers to employees' IIB, which encompasses both the production of novel ideas and the implementation of those novel ideas in a specific work role. Consequently, there are good reasons to assume that an organisational culture that supports new ideas or new ways of accomplishing a work task have the potential to foster employees' IIB directly. On the basis of this the following hypothesis is suggested:

\section{Hypothesis 7: IMOC is positively related to employees' IIB}

Furthermore, it is also assumed that the relationship between IMOC and IIB is mediated through OA. As seen in Fig. 1, such a relationship represents an indirect and supplementary route of linkages of how IMOC promotes IIB compared with what was proposed in the previous hypothesis (referring to Hypothesis 7). There are two sub-steps that in common constitute this interconnected chain of linkage. The first step assumes that IMOC is having a direct impact on OA. As mentioned in the previous discussion, the concept of OA refers to employees' attitude and whether employees perceive the hospital organisation as an attractive organisation to be employed in. It is reasonable to assume that organisational culture, in this study reflected in IMOC, is having a significant impact on employees' perception of OA. According to Leekha and Sharma, organisational culture is one of the most preferred organisational attributes [52]. Previous research supports well that employee perception of organisational culture is related to employees' attitudes $[5,22,53,54]$. A previous study using the concept of IMOC in a healthcare setting has shown that IMOC is directly linked to hospital employees' perception of OA [8] as well as to employees' satisfaction [3]. Consequently, in line with previous research on the impact of organisational culture, and especially those using the IMOC construct, there are good reasons to expect that IMOC is related to $O A$. This leads to the following hypothesis:

\section{Hypothesis 8: IMOC is positively related to $O A$}

Furthermore, and this leads to the second step of linkage between IMOC, OA and IIB, when employees perceive the organisation as attractive, stemming from IMOC, it is also reasonable to assume that this positive attitude (embraced in OA) next will motivate and engage employees to devote both more time and use more mental or physical capacity and generally be more willing to work in such a way that it benefits the interest of their hospital organisation. This idea and reasoning about logic are analogous to what was suggested in Hypothesis 3 regarding the impact of SA on OA and IIB. Specifically, based on SCT [46] IMOC (similar to SA) is capable of positively driving employees' perception of OA and next strengthen employees' motivation to perform IIB. To the authors' knowledge, no previous research has examined this exact relationship in health services research. However, previous research undertaken in hospital settings has identified OA as a mediator between IMOC and aspects of work-role performance such as employee engagement and service quality provision [8]. Consequently, in line with this research, it is assumed that $\mathrm{OA}$ is functioning as a mediator between IMOC and IIB. This leads to the following final hypothesis:

Hypothesis 9: OA mediates the relationship between IMOC and employees' IIB 
All the suggested hypotheses guiding this study are summarized in Table 1.

Table 1

Hypotheses leading this study

\section{Hypothesized relationships}

$\begin{array}{ll}\mathrm{H} 1 & \text { SA is positively related to employees' IIB } \\ \mathrm{H} 2 & \text { SA is positively related to OA } \\ \mathrm{H} 3 & \text { OA mediates the relationship between } S A \text { and employees' IIB } \\ \mathrm{H} 4 & \text { IMOC is positively related to } S A \\ \mathrm{H} 5 & \text { SA mediates the relationship between IMOC and OA } \\ \mathrm{H} 6 & \text { SA mediates the relationship between IMOC and employees' IIB } \\ \mathrm{H} 7 & \text { IMOC is positively related to employees' IIB } \\ \mathrm{H} 8 & \text { IMOC is positively related to OA } \\ \mathrm{H} 9 & \text { OA mediates the relationship between IMOC and employees' IIB }\end{array}$

Note: SA Support for Autonomy, IIB Individual Innovative Behavior, OA Organizational Attractiveness, IMOC Internal Market-Oriented Culture

\section{Methods}

This study aims to examine the relationship between IMOC, SA, OA and IIB. As such, in February 2020, we distributed questionnaires to 2000 hospital employees in the counties of Inland Norway, Norway. The hospitals have close to 10000 employees, stretching over 40 sites, making it one of the largest health expert communities in its region. With over 10 divisions, the hospitals offer various services, in both psychiatric and somatic illnesses. The study was submitted to, and approved by, the hospitals' Data Protection Office and The Norwegian Centre for Research Data (NSD). All contact with hospitals went through the Director of research (DOR). The DOR forwarded any information to division managers, who furthered the information and the survey to their employees. This study used a platform called Nettskjema (www.nettskjema.no) for data collection. The participants of this study were asked to consent to the participation because participation was voluntary and anonymous. Through convenience sampling, a total of 1008 hospital employees participated in the survey, resulting in a $50.4 \%$ response rate. As summarized in Table 2, the respondents' characteristics revealed that $73 \%$ were female. The high number correlates well with the Norwegian context, where more than $80 \%$ of employees in health organisations are women [55]. Moreover, $37.3 \%$ were under the age of 45 years, and $77.5 \%$ were full-time workers. In addition, over $55 \%$ of the participants had amassed substantial work experience because they had been with the organisation for more than 10 years. While there were minor differences among divisions, it is important to note that this study focused on individual-level behaviour and not division- 
level differences. Therefore, this study offers new insights on issues related to IIB among hospital employees at the individual level.

Table 2

Personal characteristics of the study sample $(N=1008)$

\begin{tabular}{|llc|}
\hline & & $\%$ \\
\hline Sex: & Female & 73.0 \\
\hline Staff role: & Male & 27.0 \\
& Nurse & 33.0 \\
& Doctor & 8.7 \\
\hline Employed: & Others (admin. staff, other health professionals, etc.) & 58.3 \\
\hline & less than 5 years & 26.9 \\
\hline & between 6 and 10 years & 18.0 \\
\hline & between 11 and 20 years & 30.3 \\
\hline Part-time or full-time: & more than 20 years & 24.8 \\
\hline & purt-time job & 22.5 \\
\hline Age: & full-time job & 77.5 \\
\hline & younger than 45 years & 37.3 \\
\hline & between 46 and 55 years & 32.2 \\
\hline & older than 55 years & 30.5 \\
\hline
\end{tabular}

\section{Instruments}

The study used four established instruments to measure the conceptual model of the study (Fig. 1): IMOC, SA, OA and IIB. All items in the survey required participants to respond using a seven-point Likert response scale ( 1 = strongly disagree to 7 = strongly agree). In addition to survey statements, as shown in Table 2, the questionnaire included personal characteristics such as age, sex, type of employment and work role. To ensure quality in the overall research design, two experts in the field, with 34 randomly selected hospital employees, completed a pre-test. In addition, the survey was conducted in the Norwegian language. As such, several workshops with academic experts and employees were held to verify the back-to-back translation. To note, the survey used in this study is part of a larger survey research project focusing on various aspects of employee relations in health organisations. The statements used in this study are appended accordingly (see Appendix 1). 
IMOC was measured using eight items from Slåtten et al. [8]. SA was measured using five items from Amundsen [19]. OA was measured using two items from Trybou et al. [9]. IIB was measured using five items from Janssen [56] and Scott and Bruce [57]. It is important to note that the items used in this study were adjusted to the context of hospital employees in Inland Norway. All items used in this study are summarized in Table 3.

Table 3

Latent variables and claims used in the study

\begin{tabular}{|c|c|c|}
\hline $\begin{array}{l}\text { Latent } \\
\text { variable }\end{array}$ & $\begin{array}{l}\text { Claims } \\
\text { label }\end{array}$ & Claims \\
\hline \multirow[t]{8}{*}{ IMOC } & IMOC1 & $\begin{array}{l}\text { Employees have the opportunity to discuss their needs with } \\
\text { management. }\end{array}$ \\
\hline & IMOC2 & Training is seen in the context of individual needs. \\
\hline & IMOC3 & Management spends time talking to their employees when needed. \\
\hline & IMOC4 & Management wants employees to enjoy their work. \\
\hline & IMOC5 & $\begin{array}{l}\text { Management shows a sincere interest in any problems faced by } \\
\text { employees. }\end{array}$ \\
\hline & IMOC6 & $\begin{array}{l}\text { Management understands that personal problems may affect my } \\
\text { performance. }\end{array}$ \\
\hline & IMOC7 & The division's policies help meet employees' individual needs. \\
\hline & IMOC8 & $\begin{array}{l}\text { Management meets regularly to discuss issues related to employees' } \\
\text { challenges. }\end{array}$ \\
\hline \multirow[t]{5}{*}{ SA } & SA1 & My leader gives me authority over issues within my area. \\
\hline & SA2 & My leader listens to me. \\
\hline & SA3 & My leader encourages me to take the initiative. \\
\hline & SA4 & My leader is concerned that I shall work goal oriented. \\
\hline & SA5 & My leader instils motivation. \\
\hline \multirow[t]{2}{*}{ OA } & OA1 & (Hospital name) is attractive for me as a place for employment. \\
\hline & OA2 & I would recommend (Hospital name) as an employer to my friends. \\
\hline \multirow[t]{5}{*}{ IIB } & IIB1 & Create new ideas to solve problems in my job. \\
\hline & IIB2 & Search out new working methods or techniques to complete my work. \\
\hline & IIB3 & Investigate and find ways to implement my ideas. \\
\hline & IIB4 & Promote my ideas so others might use them in their work. \\
\hline & IIB5 & Try out new ideas in my work. \\
\hline
\end{tabular}




\section{Data analysis}

Partial least squares structural equation modelling (PLS-SEM) was employed to test the conceptual models, using the software SmartPLS 3 [58]. The first step in evaluating PLS-SEM results involved examining the measurement model, consisting of only reflective measures. The second step was to assess the structural model. Based on the PLS-SEM results, mediator effects were also estimated and analysed. To test the mediator effect, the bootstrapping test of Zhao et al. [59] was used, to assess whether the direct and indirect effects are statistically significant, and the combination of these two tests determines the degree of mediator effect. We followed the 'rules of thumb' by Hair et al. $[60,61,62]$ when assessing the quality of the measurement and structural model results.

\section{Results}

\section{Measurement model}

In an assessment of the reflective measurement model, we examined convergent validity, internal consistency reliability and discriminant validity. Convergent validity is the extent a claim correlates positively with alternative claims of the same construct and was evaluated with loadings of the claims and average variance extracted (AVE). Internal consistency reliability was evaluated by looking at the intercorrelations of the observed claims within a construct and was evaluated with composite reliability and Cronbach's alpha. Discriminant validity is the extent to which a construct is distinct from other constructs, and is assessed in this study with the heterotrait-monotrait (HTMT) ratio of correlation between constructs. The HTMT test reveal whether the HTMT value is significantly different from 1 , or more precisely, if the $95 \%$ confidence interval of the HTMT statistic did not include a value of 1 . As can be seen in Table 4, all 'rules of thumb' criteria have been met, providing support for both a reliable and valid measurement model. 
Table 4

Results of the measurement model for the constructs' internal market-oriented culture (IMOC), support for autonomy (SA), organisation attractiveness (OA) and individual innovative behaviour (IIB)

\begin{tabular}{|c|c|c|c|c|c|c|}
\hline \multirow[b]{2}{*}{$\begin{array}{l}\text { Latent } \\
\text { variable }\end{array}$} & \multirow[b]{2}{*}{$\begin{array}{l}\text { Claims } \\
\text { label }\end{array}$} & \multicolumn{2}{|c|}{ Convergent validity } & \multicolumn{2}{|c|}{$\begin{array}{l}\text { Internal consistency } \\
\text { reliability }\end{array}$} & \multirow{2}{*}{$\begin{array}{l}\text { Discriminant validity } \\
\text { HTMT criterion* }\end{array}$} \\
\hline & & $\begin{array}{l}\text { Indicator } \\
\text { reliability }\end{array}$ & $\operatorname{AVE}^{*}$ & $\begin{array}{l}\text { Composite } \\
\text { reliability }\end{array}$ & $\begin{array}{l}\text { Cronbach's } \\
\text { alpha }\end{array}$ & \\
\hline $\begin{array}{l}\text { 'Rule of } \\
\text { thumb' }\end{array}$ & & $\begin{array}{l}\text { Loading > } \\
0.7\end{array}$ & $>0.5$ & $0.7-0.95$ & $0.7-0.95$ & $\begin{array}{l}\text { HTMT interval does } \\
\text { not include } 1\end{array}$ \\
\hline \multirow[t]{8}{*}{ IMOC } & IMOC1 & 0.84 & \multirow[t]{8}{*}{0.73} & \multirow[t]{8}{*}{0.95} & \multirow[t]{8}{*}{0.94} & \multirow[t]{8}{*}{ Yes } \\
\hline & IMOC2 & 0.76 & & & & \\
\hline & IMOC3 & 0.89 & & & & \\
\hline & IMOC4 & 0.86 & & & & \\
\hline & IMOC5 & 0.90 & & & & \\
\hline & IMOC6 & 0.84 & & & & \\
\hline & IMOC7 & 0.82 & & & & \\
\hline & IMOC8 & 0.90 & & & & \\
\hline \multirow[t]{5}{*}{ SA } & SA1 & 0.84 & \multirow[t]{5}{*}{0.80} & \multirow[t]{5}{*}{0.95} & \multirow[t]{5}{*}{0.93} & \multirow[t]{5}{*}{ Yes } \\
\hline & SA2 & 0.93 & & & & \\
\hline & SA3 & 0.93 & & & & \\
\hline & SA4 & 0.85 & & & & \\
\hline & SA5 & 0.92 & & & & \\
\hline \multirow[t]{2}{*}{ OA } & OA1 & 0.96 & \multirow[t]{2}{*}{0.93} & \multirow[t]{2}{*}{0.95} & \multirow[t]{2}{*}{0.93} & \multirow[t]{2}{*}{ Yes } \\
\hline & OA2 & 0.96 & & & & \\
\hline \multirow[t]{5}{*}{ IIB } & IIB1 & 0.86 & \multirow[t]{5}{*}{0.77} & \multirow[t]{5}{*}{0.94} & \multirow[t]{5}{*}{0.92} & \multirow[t]{5}{*}{ Yes } \\
\hline & IIB2 & 0.88 & & & & \\
\hline & IIB3 & 0.89 & & & & \\
\hline & IIB4 & 0.88 & & & & \\
\hline & IIB5 & 0.87 & & & & \\
\hline
\end{tabular}


Before assessing the structural model, multicollinearity between the latent constructs was examined by looking at the variance inflation factor (VIF) values. VIF values above 5 indicate multicollinearity issues [62]. All VIF values were lower than 4, indicating no multicollinearity problems. The direct effects in the structural model are shown in Fig. 2. For the endogenous constructs, the model's in-sample predictive power was examined with $R^{2}$. Based on the 'rules of thumb', the $R^{2}$ value was strong for SA (0.75), moderate for OA (0.42) and weak for IIB (0.23). Acceptable $R^{2}$ are based on the context, and in some cases $R^{2}$ at 0.10 is considered satisfactory $[61,62]$. It is important to note that, first the results of the direct-path relationships are presented, followed by the results of the proposed mediating relationships.

All the standardized direct-path coefficients were statistically significant at the 1 per cent significance level, except the non-significant coefficient between IMOC and IIB. The direct-path coefficient between IMOC and SA was highest $(\beta=0.87)$, second-highest between IMOC and $O A(\beta=0.45)$ and third-highest between SA and IIB $(\beta=0.37)$. The direct relationship between SA and IIB was positive $(\beta=0.37)$, supporting $\mathrm{H} 1$. $\mathrm{H} 2$ and $\mathrm{H} 4$ were also supported because the direct relationships between $\mathrm{SA}$ and $\mathrm{OA}$ and between IMOC and SA were significantly positive ( $\beta=0.22$ and $\beta=0.87$, respectively). There was a nonsignificant direct relationship between IMOC and IIB $(\beta=-0.09)$, and thus $\mathrm{H} 7$ got no support. Finally, there was a positive direct relationship between IMOC and OA $(\beta=0.45)$, supporting $\mathrm{H} 8$.

We used the bootstrapping test of Zhao et al. [59] to test mediation. Briefly, this test uses bootstrapping to assess whether the direct and indirect effects are statistically significant, and the combination of these two tests determines whether there exist direct effects only-without mediation, no-effect non-mediation, complementary mediation, competitive mediation (direct and indirect effects are significant, but opposite direction) or indirect-only mediation. The tests of the mediator effect show that OA complementarily mediates the relationship between SA and IIB, with a significant indirect effect of $\beta=0.06$ (Table 5), giving support for $\mathrm{H} 3$. SA complementarily mediates the relationship between IMOC and OA (indirect effect of $\beta=0.19$ ), supporting H5. The direct effects between IMOC and IIB were not statistically significant, implying that complementary mediation was not possible for $\mathrm{H} 6$ and $\mathrm{H} 9$. Our findings show that the statistically significant positive indirect effect of SA between IMOC and IIB was $\beta=0.32$, indicating an indirect-only mediator effect, supporting $\mathrm{H} 6$. OA showed a significant positive indirect effect $(\beta=0.11)$ and an indirect-only mediator effect between IMOC and IIB, and thus $\mathrm{H} 9$ received support. 
Table 5

Test of mediator effect of organisational attractiveness (OA) and support for autonomy (SA)

\begin{tabular}{|c|c|c|c|c|c|}
\hline Hypothesis & Effect & Mediator & Direct effect ${ }^{a}$ & Indirect effect ${ }^{\mathrm{a}}$ & Mediator effect ${ }^{b}$ \\
\hline H3 & $\mathrm{SA} \rightarrow \mathrm{IIB}$ & $\mathrm{OA}$ & $0.369^{\star \star \star}$ & $0.055^{\star \star \star}$ & Complementary \\
\hline H5 & $\mathrm{IMOC} \rightarrow \mathrm{OA}$ & SA & $0.446^{\star \star \star}$ & $0.191^{\star \star \star}$ & Complementary \\
\hline $\mathrm{H} 6$ & $\mathrm{IMOC} \rightarrow \mathrm{IIB}$ & SA & -0.092 & $0.319^{\star \star \star}$ & Indirect-only \\
\hline H9 & $\mathrm{IMOC} \rightarrow \mathrm{IIB}$ & OA & -0.092 & $0.110^{\star \star \star}$ & Indirect-only \\
\hline
\end{tabular}

\section{Discussion}

According to Carlucci and Schiuma, there is a need for more knowledge 'about the role and the value of intangible resources in performance improvement' [63] within research in healthcare organisations. This study contributes to this call for more research by focusing on IMOC and SA reflecting an organisational culture and climatic resource, respectively. To the authors' knowledge, this is one of the pioneering studies within health services research that both includes and specifically examines the two types of organisational resources (referring to IMOC and SA) in a hospital setting.

Organisational climate 'indicates rather superficial elements such as employees' reactions, opinions and tendencies regarding changing or conflictual organization contexts' [63]. In this study, the climatic conditions are about employees' supportiveness from leadership. Specifically, SA focuses on the domain of work context and specifically on the conditions regarding the work role that employees possess. Specifically, SA refers to the interpersonal relationship between employees and their direct leader and whether this interpersonal work context is perceived or considered as motivating, appealing and encouraging [15]. As the findings from this study reveal, it is the climatic (organisational) resource provided by leaders' SA that is capitalised in different ways in hospital organisations.

SA was found to have a direct impact on employees' level of IIB $(\beta=0.37)$. When considering the impact of all factors proposed to be directly related to IIB, the impact of SA was found to be the most influential. To the authors' knowledge, this is among the initial studies within health services research to examine this relationship. This finding illustrates the importance of having a supportive leadership in the hospital organisation because it strongly triggers, stimulates and promotes the capability of employees to act innovatively within their respective work role. As such, the findings revealing a strong relationship between SA and IIB underline the statement of Hocine and Zhang stating 'people are most creative [an implicit part of IIB] when they feel motivated' [36]. 
Although SA has impact on behavioural outcomes manifested in their IIB, this study also reveals that SA has a direct impact on employees' cognition. Specifically, it was found that SA has a direct relationship with employees' perception of $\mathrm{OA}(\beta=0.22)$. OA in this study is considered as a cognitive construct and refers to employees' attitude regarding how attractive they perceive it is to be employed in this hospital organisation. In the article by Slåtten et al., the authors state that 'future research could include other factors that potentially promote $O A^{\prime}$ [ 8 ] and specifically recommend examining the effect of leadership styles. This study contributes with new knowledge about the impact of SA on employees' perception of $\mathrm{OA}$ in a hospital setting. Consequently, SA as climatic (organisational) resource is an important driver to employees' attitudes towards $O A$ of their employer. As such, the relationship revealed in this study finds support in the work of Mesfin et al., who state: 'organizational climate [in this study manifested in SA] has a strong influence on employees' [21].

As discussed above, SA was found to be directly related to both employees' IIB and OA. This is an interesting contribution in itself. However, this study also contributes to revealing that the attitude embraced in the concept of OA has a mediation role between SA and IIB. Specifically, based on the test of the mediator suggested by Zhao et al. [59] undertaken in this study, it was found that OA is functioning as what Zhao et al. label the existence of a complementary mediation [59]. Explicitly, this means that there are two routes of impact that do not substitute each other but in contrast, simultaneously are capable of having an impact on the level of employees' IIB in hospital organisations. Specifically, one route goes directly from SA to IIB and the second route works indirectly from SA via OA and finally has an impact on employees' IIB. The important role of OA in this relationship, considering hospital organisations, is well formulated by Trybou et al., who state that 'hospital attractiveness is of major importance' [9]. In a similar vein, Slåtten et al. suggest that $\mathrm{OA}$ is 'something that needs to be focused on, maintained, and cultivated if they [referring to hospital managers] are serious about making their workplace highly attractive in a very competitive market' [8].

As this study has shown, SA is an imperative climate (organisational) resource. Consequently, SA may be labelled as the first step that hospital organisations can potentially take advantage of or capitalise on both in the relationship to employees' level of IIB and also employees' perception of OA. An implication of this is the importance for hospital organisations to continuously invest time and energy to develop and strengthen the SA of leaders. Such investments can be done in multiple ways. Some examples are through regular internal workshops in the respective hospitals, a leadership training programme in cooperation with external actors (e.g. universities), open feedback-reflection-action (FRA) seminars where both leaders and representatives from employees participate, discussing the best SA practice in the organisation. Another way to develop SA is using confidential and standard employee surveys that are repeated regularly. An advantage of using standard surveys is that they make it possible for hospital managers to track potential changes and trends of how employees experience the SA from their leaders in the organisation. No matter how the investment in SA is done, the overriding goal should be to help leaders to become more conscious and make progress in how to perform and 'deliver' SA in a way that is beneficial for the hospital organisation. As this study indicates, those hospitals that take the cost by investing in a climatic (organisational) resource of SA will attain multiple paybacks or return on such 
resource investment because it capitalises on both positive growth in employees' perception of the attractiveness of the hospital organisations (referring to $O A$ ) while simultaneously it contributes both directly and indirectly (through OA) to increase the level of employees' innovative work behaviour (referring to IIB).

SA is a significant organisational (climatic) resource for hospital managers to consider. However, as this study reveals, organisational culture also represents a significant organisational resource for hospital managers to consider. Some would even say that organisational culture is more important and fundamental than organisational climate. As Carlucci and Schiuma noted, 'climate can be understood as a surface manifestation of culture' [63]. Similarly, Banaszak-Holl et al. noted that organisational culture 'pervades all aspects of organizational life' [4]. Furthermore, organisational culture is said to be a 'basic managerial tool for improving the work environment' [4] that is initiated and promoted by top management. Organisational culture in this study is represented by the organisational (culture) resource embraced in the concept of IMOC and reflects a type of organisational culture that is 'purposely or intentionally directed towards employees in the organization' [3]. The results provide empirical support that IMOC is important for hospital organisations in several ways.

The findings reveal that IMOC has a powerful impact on SA of leaders $(\beta=0.87)$. IMOC explains $75 \%$ of the variance in SA. This is the very first study within health services research that examines the impact of IMOC on SA in a hospital setting. The findings reveal that IMOC has a substantial influence on SA of leaders in hospital organisations. It highlights that IMOC 'provides the rules for behaviour' [5] regarding how SA of leaders is performed. Furthermore, it shows how an organisational (culture) resource (referring to IMOC) is able to form and shape the organisational (climatic) resource (referring to $S A$ ) in an organisation.

IMOC was also related to the formation of employees' attitude regarding the way they perceive the hospital organisation as a great place to work or not (referring to OA). This finding is in line with a study by Slåtten et al. [8] who also found a positive relationship between IMOC and OA in a study of hospital employees. However, this study extends previous research of the impact of IMOC by examining the different patterns of relationships associated with OA. Specifically, the direct impact of IMOC on OA was found to be twice the size of the direct impact of SA on OA (respectively, $\beta=0.45$ versus $\beta=0.22$ ). Furthermore, in addition to the direct relationship, this study also found IMOC to have an indirect impact via SA on OA. Specifically, based on the test of the mediator suggested of Zhao et al. [59], it was found that SA is functioning as what Zhao et al. label as the existence of a 'complementary mediation' [59]. A complementary mediation implies that two pathways simultaneously lead to OA. In total, the direct or indirect impact of IMOC collectively explains $42 \%$ of the variance in OA. Consequently, this finding proposes that 'organizational culture [in this study represented by IMOC] can be best described as a critical first step towards creating satisfactory work environments' [4].

Based on ideas and suggestions in previous research [8], it was anticipated that IMOC should have a direct impact on IIB. Surprisingly, the results identified a non-significant direct relationship between IMOC 
and IIB. However, on the other hand, the statistical analyses revealed the existence of a relatively complicated and multifaceted pattern that explains the links between IMOC and IIB. Specifically, it was found that the relationship between IMOC and IIB works through what Zhao et al. [59] label as an 'indirect-only' mediator effect. Two 'indirect-only' mediating effects of IMOC on IIB were identified, one that works through SA and another that works through OA. The implication for hospital managers regarding IIB can be summarized in two aspects. First, hospital managers need to recognise that it is only when hospital employees perceive the OA and SA of leaders in their organisation as positive that employees will be willing and motivated to devote the necessary time and energy to do the extra-role effort embraced in IIB. Second, hospital managers should always recognise that it is not enough to just focus on IMOC in isolation. Hospital managers should consider IMOC as a 'basic managerial tool' [4]. However, findings from this study show that hospital managers should strive to understand IMOC in a broader employee perspective. Specifically, they should continuously acquire updated knowledge about how and in what way IMOC is able to have a positive impact on the 'inner-life' of their employees in the hospital organisation (referring to OA and SA). Consequently, when taking such a broader employee perspective on IMOC while simultaneously investing to constantly uphold, cultivate and develop IMOC, it will in tandem with SA lead to a positive resource capitalisation manifested in both a growth in employees' perception of OA as well as employees' level of innovative behaviour (IIB).

\section{Limitations And Future Research}

There are several opportunities for future research based on the limitations of this study. The following four areas for future research are recommended.

First, this study is limited in its cross-sectional design. For instance, the empirical data in this study was collected at one point of the time, from one health organization. Consequently, the results of this study should not be generalized to other health organizations. Regardless, the results of this study can function as a step stone for future research to include various health organizations, including testing causal and reversed casual relationships. This is in order to minimize method bias. In addition, the limitations linked to online survey are known to suffer from self-selection bias and shared response bias, due to its nature in self-report measures. Consequently, as suggested by Hair et al. [2018], these limitations might reveal that future studies should employ a time lag in data gathering.

Second, this study is limited to only include IMOC to reflect the organisational culture resource. However, future research should examine other types of potential cultural resources in hospital organisations. For example, one could include those culture types mentioned in the framework of Cameron and Quinn [64]. In their framework, the authors propose four types of organisational culture that could exist or be dominating in organisations. Specifically, these four types of organisational culture are clan, adhocracy, market and hierarchy. To the authors' knowledge, little research within health services research has examined the role of these four types of organisational culture. Therefore, it is highly recommended that future research should focus on culture types in the framework of Cameron and Quinn [64] and examine 
how they either individually or eventually collectively are capable of promoting desirable organisational objectives for hospital organisations.

Third, this study was also limited to only comprise SA reflecting an organisational climatic resource. As previously mentioned, the domain of organisational climate as a concept is to study organisations based on the perspective 'how things are done here'. Based on this, there are numerous opportunities to include other climatic resources in hospital organisations in future research. Specifically, studying climatic conditions from a leadership perspective could include leadership styles such as empowering leadership, transformational leadership, ambidextrous leadership, transactional leadership, charismatic leadership and so forth. There are several opportunities here. Furthermore, studying climatic conditions from an employee perspective, future research could examine climatic aspects such as cooperative climate, communication climate, learning climate, supportive climate, trusting climate, humoristic climate and so forth. These aspects of organisational climate could, similar to types of organisational culture, be studied individually or mutually. Parallel to this study, it is also possible for future research to examine how those organisational culture types suggested in the framework of Cameron and Quinn [64] (referring to clan, adhocracy, market and hierarchy) are related to those types of organisational climate suggested in this section. Such focus contributes to revealing a potential pattern of relationships of how types of organisational culture work in tandem with types of organisational climate to the achievement of the desired organisational goal for hospital organisations.

Fourth, as noted through this paper, there is little research on the two types of resource capitalisation included in this study (referring to OA and IIB). Considering the importance of OA and IIB for hospital organisations, there is a need to include both factors in future health services research. However, in addition to including $\mathrm{OA}$ and IIB, other types of resource capitalisation could be included. For example, considering the seemingly growing competition among hospitals (e.g. public versus private hospitals) in many countries, future research could include the concept of competitive power. The concept of competitive power focuses on 'a company's relative advantage in the marketplace in comparison to its most relevant competitors' [65]. 'Competitive power is reflected in such as being the first to introduce new services into the market, having more satisfied customers and hard for competitors to imitate firms' service offerings' [65]. Organisational culture is proposed to be a potential source of organisational competitive advantage [6]. By including the concept of competitive power in health services research, it will reveal what type of organisational culture, and its associated type of organisational climate, that most prominently contribute to explain the competitiveness of hospitals. Consequently, such focuses among several other options are offering the potential for new knowledge and insight, both theoretically as well as practically for future research.

\section{Conclusions}

This study contributes with new knowledge regarding how organisational culture and organisational climate function as two different types of organisational resources. The findings highlight the significance for hospital managers to invest in both IMOC and SA. By making resource investment in 
IMOC and SA, the pay-off or resource capitalisation is manifested in both a positive growth in employees' perception of OA as well as employees' level of innovative behaviour.

\section{Abbreviations}

PSF: Professional service firms; RBV: Resource-based view; SDT: Self-determination theory: LMX: Leader-member-exchange; SCT: Social cognitive theory; DOR: Director of research; IIB: Individual innovative behaviour; AS: Autonomy support; IMOC: Internal market-oriented culture; OA: Organisational attractiveness; FRA: Feedback-reflection-action; PLS-SEM: Partial least squares structural equation modelling; AVE: Average variance extracted; HTMT: Heterotrait-monotrait; VIF: Variance inflation factor; NSD: The Norwegian Centre for Research Data

\section{Declarations}

\section{Ethics and consent to participate}

This study was approved by the Norwegian Social Science Data Services (NSD) (project number 239029). The NSD is a resource centre and ethics committee for academic research in Norway. The study was also approved by the Data Protection Office of the hospital organization in this study. In accordance with the Personal Data Act §§2-7 and 8 no. 1, the participants were given written information about the project and gave their consent by choosing to participate in the study and completing the online questionnaire.

\section{Consent for publication}

Not applicable

\section{Competing interests}

The authors declare that they have no competing interests.

\section{Funding}

Not applicable

\section{Availability of data and material}

The datasets used and/or analysed during the current study are available from the corresponding author on reasonable request.

\section{Authors' contributions}

BRM led the development of the questionnaire, data collection and draft of the manuscript. TS led the development and mainly drafted this manuscript. GL contributed to the development of the questionnaire, 
statistical analysis, interpretation of data and general input into the manuscript. All three authors approved the final draft.

\section{Acknowledgements}

The authors express their gratitude to the study subjects for their participation in this research.

\section{References}

1. Ind N. Living the brand. How to transform every member of your organization into a brand champion. London: Kogan Page Limited; 2010.

2. Liedtka JM, Haskins ME, Rosenblum JW, Weber J. The generative cycle: linking knowledge and relationships. Sloan Manag Rev. 1997, Fall:47-58.

3. Slåtten T, Lien G, Lupina E, Gravingen KA. Promoting an Internal Market-Oriented Culture (IMOC) in healthcare services. J of Serv Sci Res. 2019;11(2):157-82.

4. Banaszak-Holl J, Castle NG, Lin MK, Shrivastwa N, Spreitzer G. The role of organizational culture in retaining nursing workforce. The Gerontologist. 2015;55(3):462-71.

5. Tsai Y. Relationship between organizational culture, leadership behavior and job satisfaction. BMC Health Services Research. 2011;11:1-9.

6. Barney JB. Organizational culture: can it be a source of sustained competitive advantage. Academy of Management Review. 1986;11(3):656-65.

7. Lings IN \& Greenley GE. Measuring internal market orientation. Journal of Service Research 2005;7(3):290-305.

8. Slåtten T, Lien G, Svenkerud PJ. The role of organizational attractiveness in an internal marketoriented culture (IMOC): A study of hospital frontline employees. BMC Health Services Research. 2019;19(1):307.

9. Trybou J, Gemmel P, Van Vaerenbergh Y, Annemans L. Hospital-physician relations: the relative importance of economic, relational and professional attributes to organizational attractiveness. BMC Health Services Research. 2014;14(1):232.

10. Yan D, Wen F, Li X, Zhang Y. The relationship between psychological capital and innovation behavior in Chinese nurses. Journal of Nursing Management. 2020;28(3):471-9.

11. Slåtten T, Lien G, Horn CMF, Pedersen E. The links between psychological capital, social capital, and work-related performance - A study of service sales representatives. Total Quality Management \& Business Excellence. 2019;30(sup1):S195-S209.

12. Korzilius H, Bücker JJLE, Beerlage S. Multiculturalism and innovative work behavior: The mediating role of cultural intelligence. International Journal of Intercultural Relations. 2017;56:13-24.

13. Oppi C, Bagheri A, Vagnoni E. Antecedents of innovative work behaviour in healthcare: does efficacy play a role? International Journal of Public Sector Management. 2019;33(1):45-61.

14. Wernerfelt B. A resource-based view of firm. Strat Manag J. 1984;5(2):171-80. 
15. Gillet N, Gagné M, Sauvagère S, Fouquereau E. The role of supervisor autonomy support, organizational support, and autonomous and controlled motivation in predicting employees' satisfaction and turnover intentions. European Journal of Work and Organizational Psychology. 2013;22(4):450-60.

16. Deci EL, Ryan RM. Facilitating optimal motivation and psychological well-being across life's domains. Canadian Psychology/Psychologie Canadienne. 2008;49(1):14.

17. Gagné M, Deci EL. Self-determination theory and work motivation. Journal of Organizational Behavior. 2005;26(4):331-62.

18. Ryan RM, Deci EL. Overview of self-determination theory: An organismic dialectical perspective. In: Deci EL, Ryan RM, editors. Handbook of self-determination research. Rochester, NY: University of Rochester Press; 2002. p. 3-33.

19. Amundsen S. Empowerment i arbeidslivet - Et myndiggjøringsperspektiv på ledelse, selvledelse og medarbeiderskap. Oslo: Cappelen Damm Akademisk; 2019.

20. Kanat-Maymon Y, Reizer A. Supervisors' autonomy support as a predictor of job performance trajectories. Applied Psychology: An International Review. 2017;66(3):468-86.

21. Mesfin D, Woldie M, Adamu A, Bekele F. Perceived organizational culture and its relationship with job satisfaction in primary hospitals of Jimma zone and Jimma town administration, correlational study. BMC Health Services Research. 2020;20(1):438.

22. Zachariadou T, Zannetos S, Pavlakis A. Organizational culture in the primary healthcare setting of Cyprus. BMC Health Services Research. 2013;13(1):1-8.

23. Dastmalchian A, Lee S, Ng I. The interplay between organizational and national cultures: a comparison of organizational practices in Canada and South Korea using the Competing Values Framework. International Journal of Human Resource Management. 2000;11(2):388-412.

24. Chow CW, Harrison GL, McKinnon JL, Wu A. The organizational culture of public accounting firms: Evidence from Taiwanese local and US affiliated firms. Accounting, Organizations and Society. 2002;27(4-5):347-60.

25. Yan $\mathrm{YH}, \mathrm{Kung}, \mathrm{CM}$. Hospital image and compensation/benefit system on organizational attractiveness. Public Health. 2017;2(1):33-41.

26. Berthon P, Ewing M, Hah L. Captivating company: dimension of attractiveness in employer branding. Int J Advertising. 2005;24(2):151-72.

27. Theurer CP, Tumasjan A, Welpe IM, Lievens F. Employer branding: a brand equity-based literature review and research agenda. Int J Manag Rev. 2018;1:155-79.

28. https://www.greatplacetowork.com/best-workplaces/100-best/2018 (accessed January 21, 2020).

29. Aiman-Smith L, Bauer T, Cable D. Are you attracted? Do you intend to pursue? A recruiting policycapturing study. Journal of Business and Psychology. 2001;16(2):219-37.

30. Hult GTM, Hurley RF, Knight GA. Innovativeness: its antecedents and impact on business performance. Industrial Mark Manag. 2004;33(5):429-38. 
31. Mutonyi BR, Slåtten T, Lien G. Empowering leadership, work group cohesiveness, individual learning orientation and individual innovative behaviour in the public sector: empirical evidence from Norway. Int J Pub Lead. 2020;6(2):175-98.

32. Mutonyi BR, Slåtten T, Lien G. Organizational climate and creative performance in the public sector. Eur Bus Rev. 2020;32(4).

33. Avby G, Kjellstöm S. LearnOvation: an intervention to foster exploration and exploitation behavior in health care management in daily practice. BMC Health Serv Res. 2019;19(319):1-9.

34. Battistelli A, Montani F, Odoardi C. The impact of feedback from job and task autonomy in the relationship between dispositional resistance to change and innovative work behavior. Euro $\mathrm{J}$ Work Org Psy. 2013;22(1):26-41.

35. Gillet N, Colombat P, Michinov E, Pronost AM, Fouquereau E. Procedural justice, supervisor autonomy support, work satisfaction, organizational identification and job performance: The mediating role of need satisfaction and perceived organizational support. Journal of Advanced Nursing. 2013;69(11):2560-71.

36. Hocine Z, Zhang J. Autonomy support: Explaining the path from leadership to employee creative performance. Open Journal of Social Sciences. 2014;2(6):417-23.

37. Slåtten T, Mehmetoglu M. Antecedents and effects of engaged frontline employees - A study from the hospitality industry. Managing Service Quality: An International Journal. 2011;21(1):88-107.

38. Graen GB, Uhl-Bien M. Relationship-based approach to leadership: Development of leader-member exchange (LMX) theory of leadership over 25 years: Applying a multi-level multi-domain perspective. Leadership Quarterly. 1995;6(2):219-47.

39. Slåtten T. Determinants and effects of employee's creative self-efficacy on innovative activities. International Journal of Quality and Service Sciences. 2014;6(4):326-47.

40. Blau PM. Exchange and Power in Social Life. New York, NY: Wiley; 1964.

41. Gouldner AW. The Norm of Reciprocity: A Preliminary Statement. American Sociological Review. 1960;25(2):161-78.

42. García-Sierra R, Fernández-Castro J. Relationships between leadership, structural empowerment, and engagement in nurses. Journal of Advanced Nursing. 2018;74(12):2809-19.

43. Moloney W, Boxall P, Parsons M, Cheung G. Factors predicting Registered Nurses' intentions to leave their organization and profession: A job demands-resources framework. Journal of Advanced Nursing. 2018;74(4):864-75.

44. Reeve J. Giving and summoning autonomy support in hierarchical relationships. Social and Personality Psychology Compass. 2015;9(8):406-18.

45. Benioff M. Fortune 100 Best Companies to Work For 2018. 2018 [Available from: https://www.greatplacetowork.com/best-workplaces/100-best/2018].

46. Aloustani S, Atashzadeh-Shoorideh F, Zagheri-Tafreshi M, Nasiri M, Barkhordari-Sharifabad M, Skerrett V. Association between ethical leadership, ethical climate and organizational citizenship 
behavior from nurses' perspective: a descriptive correlational study. BMC Nursing. 2020;19(15):1-8.

47. Homburg C, Pflesser C. A multiple-layer model of market-oriented organizational culture: Measurement issues and performance outcomes. Journal of Marketing Research. 2000;37(4):44962.

48. Casida JJ, Pinto-Zipp G. Leadership-organizational culture relationship in nursing units of acute care hospitals. Nursing Economics. 2008;26(1):7-15.

49. Hartnell CA, Ou AY, Kinicki A. Organizational culture and organizational effectiveness: a metaanalytic investigation of the competing values framework's theoretical suppositions. American Psychological Association. 2011;96(4):677-94.

50. Scott T, Mannion R, Davies H, Marshall M. The quantitative measurement of organizational culture in health care: a review of the available instruments. Health Services Research. 2003;38(3):923-45.

51. Hogan SJ, Coote LV. Organizational culture, innovation, and performance: A test of Schein's model. Journal of Business Research. 2014;67(8):1609-21.

52. Leekha C, Sharma S. Employer branding: strategy for improving employer attractiveness. Int J Org Analysis. 2014;22(1):48-60.

53. O'Reilly CA, Chatman JA. Culture as social control: corporations, cults, and commitment. In. Cummings L, Staw B, Editors. Research in Organizational Behavior. Greenwich, CT: JAI Press; 1996: 157-200.

54. Slåtten T, Lien G, Svensson G. (2018) The value of cultivating norms for market orientation in professional service firms. Int J Serv Qual and Serv Sci. 2018;10(3):316 - 30.

55. Jensen RS, Øistad BS. Det kjønnsdelte arbeidsmarkedet på virksomhetsnivå

56. Janssen O. Job demands, perceptions of effort-reward fairness and innovative work behaviour. Journal of Occupational and Organizational Psychology. 2000;73(3):287-302.

57. Scott SG, Bruce RA. Determinants of innovative behavior: A path model of individual innovation in the workplace. Academy of Management Journal. 1994;37(3):580-607.

58. Ringle CM, Wende S, Becker J-M. SmartPLS 32015 [Available from: https://www.smartpls.com/].

59. Zhao X, Lynch JGJ, Chen Q. Reconsidering Baron and Kenny: myths and truths about mediation analysis. J Consumer Research. 2010;37:197-206.

60. Hair Jr JF, Sarstedt M, Ringle CM, Gudergan SP. Advanced Issues in Partial Least Squares Structural Equation Modeling. London, UK: SAGE; 2018.

61. Hair JF, Hult GTM, Ringle C, Sarstedt M. A Primer on Partial Least Squares Structural Equation Modeling (PLS-SEM). 2nd ed. London, UK: SAGE; 2017.

62. Hair JF, Risher JJ, Sarstedt M, Ringle CM. When to use and how to report the results of PLS-SEM. European Business Review. 2019;31(1):2-24.

63. Carlucci D, Schiuma G. Organizational climate as performance driver: health care workers' perception in a large hospital. J Health Manag. 2014;16(4):583-94. 
64. Cameron KS, Quinn RE. Diagnosing and Changing Organizational Culture: Based on the Competing Value Framework. New York: Wiley; 2012.

65. Make EJ, Slåtten T. How can entrepreneurial orientation be promoted in service firms and what are the potential effects? An empirical study of frontline employees. Int $\mathrm{J}$ of Multidisciplinarity in Bus and Sci. 2020;6(9):13-22.

\section{Figures}

Organisational resources

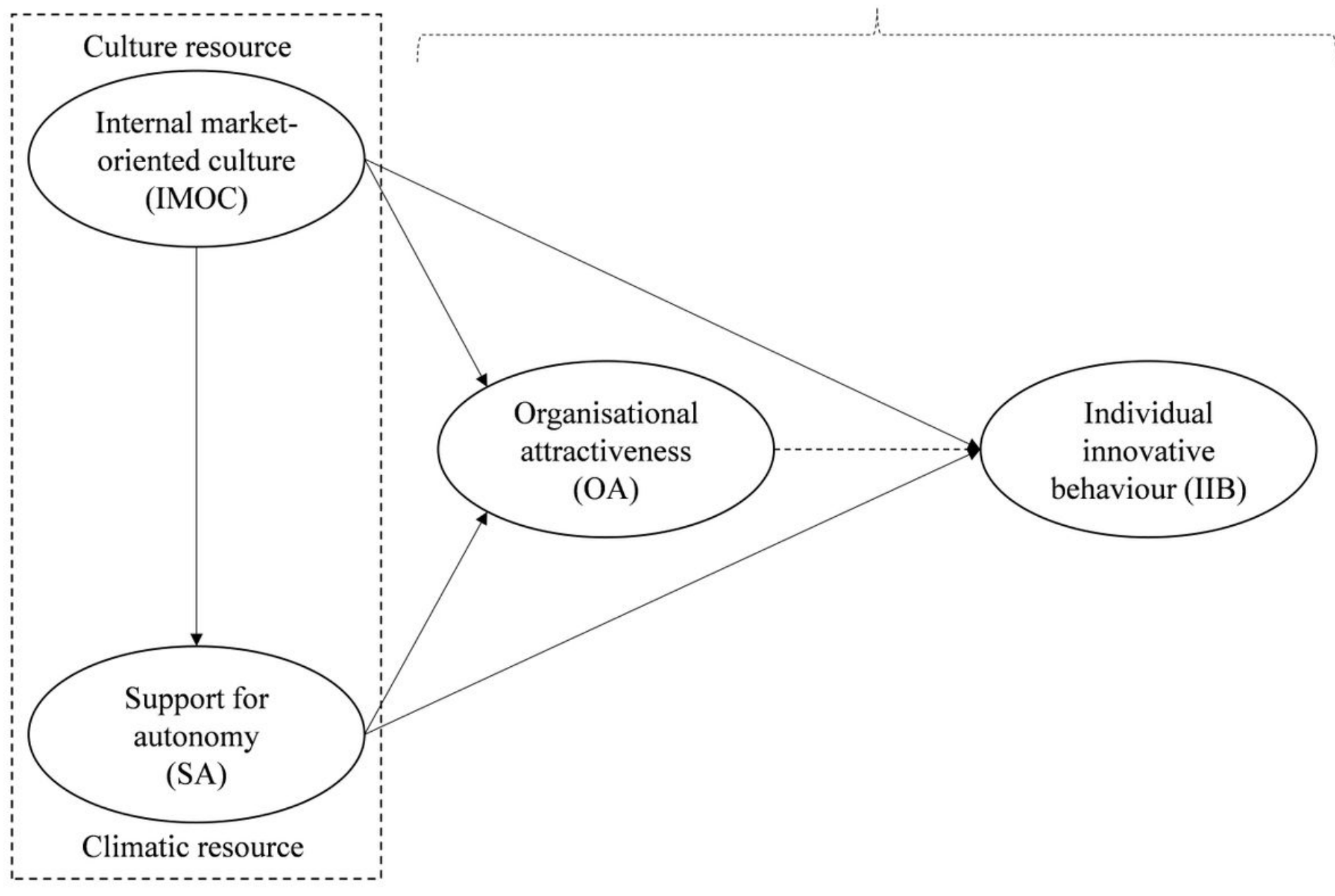

\section{Figure 1}

Conceptual model of the study of the relationship between organisational resources and resource capitalisation 
Organisational resources

Resource capitalisation

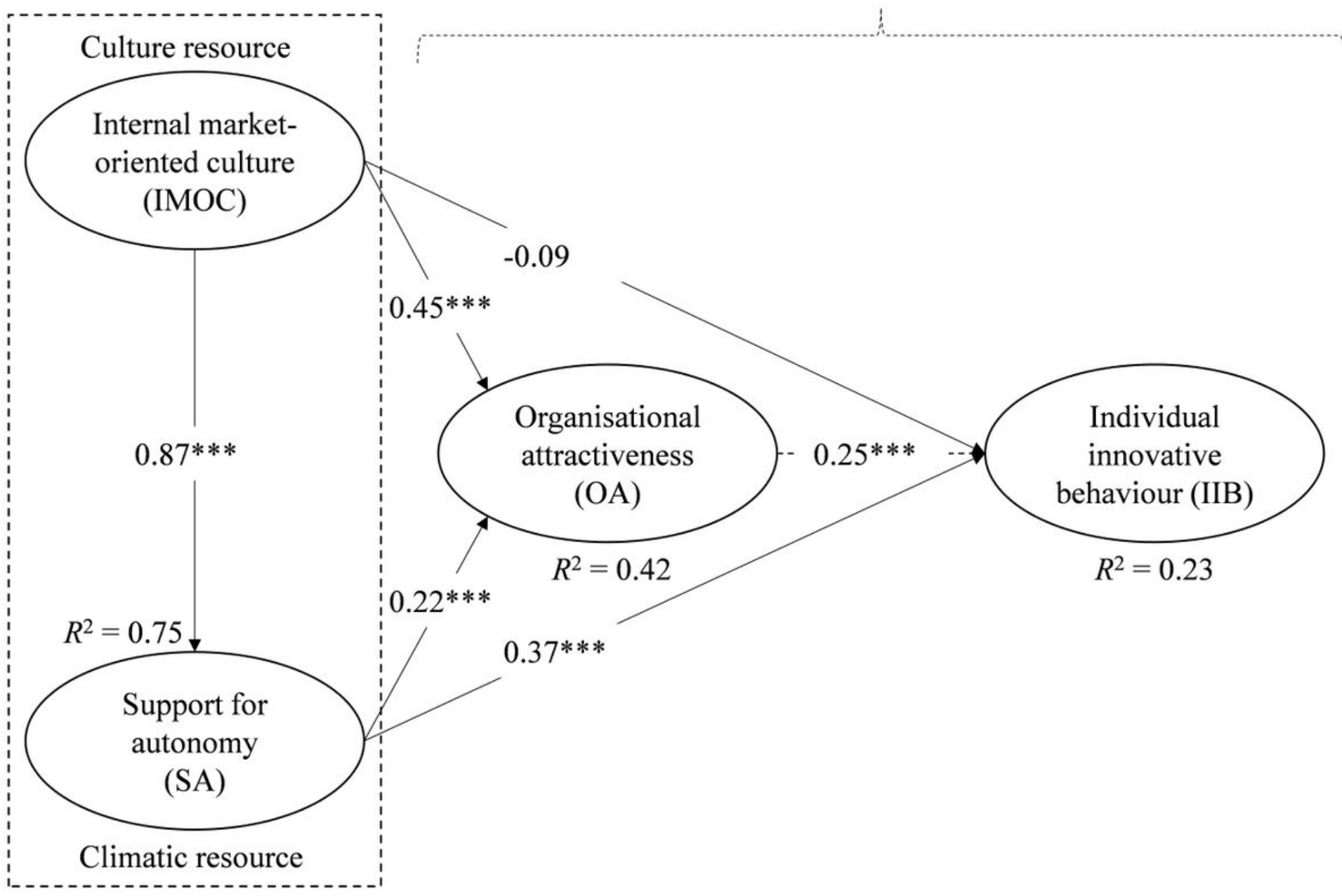

Figure 2

Results of the structural model to analyse the relationships between organisational resources and resource capitalisation. Standardized coefficients $(* \star *<0.01)$

\section{Supplementary Files}

This is a list of supplementary files associated with this preprint. Click to download.

- APPENDIX1QUESTIONNAIREDEVELOPEDFORTHISSTUDYv1.docx 